\title{
Dear readers
}

Welcome to the first issue of the Journal of Project, Program \& Portfolio Management.

We had three objectives in setting up this journal. First, we felt that as program and portfolio management are gaining more prominence we needed a journal that also gave importance to these aspects of implementing organizational strategies through projects. The second aim was to increase professional and public access to knowledge resources by being part of the open journal system, which was established by the Public Knowledge Project to improve the scholarly and public quality of research. Finally, we wanted to establish a journal that bridged theory and practice by including both journal articles as well as case studies so that academics and practitioners will find a single forum to publish their work.

Thanks to Michel Thiry for helping to solicit papers from those who wanted to contribute to the area of program management and we have two such contributions in this issue. The first, by Gilman Tam, argues that while sustainability has been given importance in the project management literature it has not been prominent in the program management literature. The author proposes a way to incorporate sustainability elements in the program management process. In the second work, Somanchi and Dwivedula explain, through a real-life case study, how program management has been successfully implemented in a large-scale information technology project in India.

The other two papers published in this issue offer some interesting insights for project managers. Murray-Webster and Pellegrinelli propose an enhancement to conventional risk management practices to provide a more holistic approach, which also aligns with intuitive practices of experienced practitioners. Russo and Sbragia report on a study conducted to investigate whether managers showing entrepreneurial characteristics are associated with projects that were more successful from an organizational viewpoint.

The journal could not have been published without the help of several people. Sasha Kovac, a Master of Project Management student at UTS, configured the OJS software to create a skeleton for this publication. Gabrielle Gardiner and Elizabeth Mulhollann from UTSeScholarship were always available when help was required. The community of journal editors at UTSepress whose advice and publications helped shape this journal.

We look forward to some valuable feedback from readers on how we can improve the journal and make it more useful.

A second issue is planned for publication for the end of 2010. Papers and case studies are due by the end of September.

Happy Reading!

Shankar Sankaran

Chief Editor

School of the Built Environment

University of Technology Sydney 